\title{
PERBEDAAN HASIL BELAJAR MATEMATIKA SISWA DALAM PEMBELAJARAN MENGGUNAKAN METODE INQUIRY DAN EKSPOSITORI KELAS X SMKN 12 SAMARINDA
}

\author{
Sugeng ${ }^{1)}$ \\ Lina Andriani ${ }^{2)}$ \\ P.M. Labulan ${ }^{3)}$ \\ 1), 2), 3) Program Studi Pendidikan Matematika, Universitas Mulawarman \\ Email: ${ }^{1)}$ sugeng@fkip.unmul.ac.id
}

\begin{abstract}
ABSTRAK
Penelitian ini bertujuan menyelidiki perbedaan hasil belajar matematika dalam pembelajaran dengan metode inquiry dan ekspositori siswa kelas X SMKN 12 Samarinda tahun pelajaran 2019/2020. Penelitian eksperimen semu ini menggunakan Nonequivalent Group Pretest Posttest Design. Populasi penelitian mencakup semua siswa kelas X SMKN 12 Samarinda. Sampel penelitian ditentukan dengan teknik Purposive Sampling dan diperoleh dua kelas, yaitu X TKJ \& X AK1 SMKN 12 Samarinda sebagai sampel penelitian. Pengambilan data menggunakan tiga instrumen, yaitu tes, observasi, dan dokumentasi. Sebelum untuk pengambilan data, soal tes diujicobakan kepada 32 siswa kelas X jurusan TKJ SMK Muhammadiyah di Loa Janan. Analisi data penelitian menggunakan teknik Independent Sample t-test pada $\alpha=0,05$. Hasil penelitian menunjukkan rata-rata skor hasil belajar matematika siswa kelompok eksperimen $(63,12)$ lebih tinggi daripada siswa kelompok kontrol $(50,84)$. Hasil uji $t$ menunjukkan nilai Sig. $=0,04$ dan tenyata lebih kecil dari taraf $\alpha=0,05$ sehingga $H o$ ditolak. Dengan demikian, terdapat perbedaan hasil belajar matematika siswa dalam pembelajaran menggunakan metode inquiry dan ekspositori kelas X SMKN 12 Samarinda tahun pelajaran 2019/2020. Berdasarkan Uji Satu Pihak (uji pihak kanan) diperoleh Sig.=0.004 sehingga $H_{0}$ ditolak, berarti pembelajaran yang menggunakan metode Inquiry menghasilkan hasil belajar yang lebih tinggi dan signifikan daripada menggunakan metode Ekspositori.
\end{abstract}

Kata kunci: Metode Inquiry, Metode Ekspositori, Hasil Belajar Matematika

\begin{abstract}
This research investigates differences in mathematical learning outcomes with inquiry and expository methods class X SMKN 12 Samarinda students in 2019/2020. This quasi-experimental study uses a Nonequivalentg group pretest-posttest design. The research population includes all class X SMKN 12 Samarinda 2019/2020. The research sample was determined by the Purposive Sampling technique and obtained two classes, namely X TKJ \& X AK1 SMKN 12 Samarinda, as a research sample. Data retrieval uses three instruments, namely tests, observations, and documentation. Before the data


collection, the test question was piloted to 32 students in class X majoring in TKJ SMK Muhammadiyah in Loa Janan. Data analysis using the Independent Sample t-test technique at $\alpha=0.05$. This study obtained an average math learning outcome score for the experimental group students (63.12) higher than students in the control group (50.84). The test result showed a sig. $=0.04$ and a score less than the level $\alpha=0.05$ so that $\mathrm{H}_{0}$ was rejected. Thus, there are differences in students' math learning outcomes using the Inquiry method and Expository of class X SMKN 12 Samarinda lesson year 2019/2020. The One-tailed Test (right-tailed test) obtained Sig. $=0.004$ so that H_0 rejected, meaning learning using the Inquiry method produces higher and significant learning outcomes than using the Expository method.

Keywords: Inquiry Method, Expository Method, Mathematical Learning Outcomes

\section{PENDAHULUAN}

Pembelajaran sebagai kegiatan terpogram mencakup desain instruktur yang menugaskan guru secara terjadwal membuat kondisi siswa untuk belajar aktif dan penyediaan sumber belajar. Kegiatan pembelajaran tersebut terjadi dalam kelas (klasikal) ataupun di luar kelas, yang melibatkan guru, siswa, kurikulum, LKPD, bahan ajar, dan lainnya. Guru berperan sebagai pengajar dan siswa adalah belajar. Berdasarkan hasil observasi, SMKN 12 Samarinda sebagai salah satu SMK yang menerapkan kurikulum 2013. Namun, berdasarkan hasil wawancara kepada salah satu guru matematika di sekolah tersebut, bahwa meskipun sekolah sudah menggunakan kurikulum 2013, guru-guru masih menggunakan metode ekspositori.

Penggunaan metode ekspositori ini, menurut alasan dari salah satu guru bahwa penerapan metode pembelajaran ekspositori lebih mudah dan tidak membebani tugas guru, karena dalam metode ekspositori tugas guru hanya ceramah dan siswa mendengarkan. Hal itu sesuai dengan maksud metode ekspositori, yaitu metode pembelajaran yang memadukan metode ceramah, tanya jawab, dan demonstrasi. Berdasarkan hasil observasi kelas, pada pembelajaran matematika menggunakan metode ekspositori, suasana kelas menjadi statis, guru lebih aktif dalam pembelajaran daripada siswa. Pembe-lajaran dimulai oleh guru dengan menyampaikan tujuan pembelajaran, kemudian guru menyajikan materi matematika dengan ceramah diiringi pen-jelasan, siswa mendengarkan penje-lasan guru dan mencatat hal-hal yang dianggap penting, guru melakukan tanya jawab berdasarkan umpan balik siswa, dan akhirnya siswa diberi tugas oleh guru untuk dikerjakan. Hal demikian akan mengakibatkan hasil belajar bidang matematika siswa menjadi rendah.

Untuk meningkatkan keaktifan, kreativitas, dan hasil belajar siswa dilakukan perubahan kegiatan belajar mengajar agar tercipta suasana dalam belajar yang efektif, kreatif, menantang dan menyenangkan. Metode pembelajaran inquiry lebih menekankan kepada kemampuan berfikir dari diri siswa untuk memecahkan masalah, melalui proses mengkonstruksi pengetahuan yang dimiliki dan menjadi bermakna berdasarkan pengalaman nyata. 
Inquiry merupakan sistem belajar mengajar yang menghendaki siswa berpikir kritis dan kreatif, dan siswa sebagai subjek yang aktif pada kegiatan belajar mengajar untuk menghasilkan informasi bermakna dari pengalaman belajarnya (Mulyasa, 2013). Menurut Syaiful Sagala (2010), metode inquiry sebagai metode pembelajaran untuk menanamkan landasan berfikir ilmiah pada diri siswa sehingga sebagai subjek belajar siswa cenderung belajar sendiri, mampu mengembangkan kreativitas, dan berfikir kritis untuk menyelesaikan masalah. Menurut Kesuma (2010), inquiry sebagai kegiatan pembelajaran berdasarkan hasil capaian dan temuan dengan menggunakan proses berpikir sistematis.

Dengan demikian, metode inkuiri sebagai metode pembelajaran yang cocok digunakan untuk memperkuat landasan berfikir ilmiah pada siswa, sehingga dalam kegiatan belajar me-ngajar, siswa akan cenderung belajar sendiri memecahkan masalah, mulai dari melakukan pengamatan, mengajukan pertanyaan, merencanakan dan penye-lidikan, mengumpulkan dan mengana-lisis data, membuat kesimpulan dan mengkomunikasikan hasil penyelidikan.

Metode ekspositori sebagai metode pengajaran yang dalam penyajian materi menggunakan ceramah, tanya jawab dan pemberian tugas (Hamiyah \& Jauhar, 2014). Penggunaan metode ini memberikan arah bagi siswa agar berusaha sendiri menemukan fakta, konsep, serta prinsip berdasarkan penjelasan guru. Menurut Muhibbin Syah (2011), metode ekspositori sebagai langkah-langkah yang direkayasa dalam pembelajaran untuk mencapai tujuan pengajaran tertentu.

Sumantri (2015) menjelaskan pembelajaran dengan metode ekspositori domi-nasi keaktifan guru berkurang. guru tidak terus berbicara di depan kelas, guru memberikan informasi sebatas pada bagian-bagian terpenting (diperlukan) saja, seperti menjelaskan konsep dan prinsip.

Berdasarkan uraian tersebut, pembelajaran menggunakan metode ekspo-sitori diawali dengan memberikan penjelasan tentang definisi-definisi, prinsip-prinsip, dan konsep materi pembelajaran yang disertai dengan contoh-contoh soal terkait dengan pemecahan masalah disajikan secara ceramah, tanya jawab, atau penugasan, dan menempatkan siswa dalam posisi pasif.

Hasil sebagai suatu perolehan akibat dilakukannya aktivitas belajar sebagai penyebab sehingga mengakibatkan input berubah secara fungsional (Purwanto, 2009). Bukti seseorang telah belajar ialah terjadinya perubahan pola perilaku pada orang itu (Hamalik, 2001).

Perubahan perilaku pada diri siswa menunjukkan adanya hasil belajar dan hal itu dapat diamati atau diukur pada unsur sikap, keterampilan dan penge-tahuannya. Menurut Hamalik (2002), perubahan yang terjadi itu sebagai suatu peningkatan dan pengem-bangan ke arah yang lebih baik daripada sebelumnya.

Matematika sebagai ilmu pengetahuan yang menekankan pola dan proses berfikir logis. Menurut Hariwijaya (2007) matematika merupakan pengeta-huan yang mengkaji pola, struktur, beserta perubahannya. Secara formal, sebagai penelaahan struktur abstrak yang 
didefinisikan secara aksiomatis, menggunakan notasi, dan logika simbolik secara tidak formal, sebagai ilmu bilangan dan angka. Menurut Hudojo (dalam Chairani, 2016) mate-matika merupakan ilmu tentang struktur dan hubungannya dengan simbol-simbol.

Dengan demikian, hasil belajar matematika siswa sebagai wujud kemampuan intelektualnya dalam bidang matematika berdasarkan latihan dan pengalaman memecahkan masalah yang terkait materi ajar matematika selama proses belajar mengajar dan dinyatakan dengan nilai matematika, terutama pada materi pokok barisan dan deret aritmatika.

\section{METODE PENELITIAN}

Penelitian yang dilakukan menggunakan metode eksperimen dengan pendekatan kuantitatif, jenisnya Quasi Experimental menggunakan desain Nonequivalent group pretest posttest.

Menurut Sugiyono (2017) pada desain itu, kedua kelompok (eksperimen dan kontrol) diuji dengan tes awal (pretest) menggunakan tes yang sama. Kelompok eksperimen diberi pembelajaran menggunakan metode Inquiry, dan kelompok kontrol menggunakan metode pembelajaran ekspositori. Setelah perlakuan selesai diberikan, kelompok eksperimen dan kontrol diberikan tes sama, dan merupakan posttest. Selanjutnya, antara hasil tes awal ataupun antara tes akhir dari kedua kelompok diperbandingkan.
Tabel 1. Quasy Experiment dengan Nonequivalent Group PretestPosttes Design

\begin{tabular}{|c|c|c|c|}
\hline Kelompok & $\begin{array}{c}\text { Pre } \\
\text { test }\end{array}$ & Perlakuan & $\begin{array}{c}\text { Post } \\
\text { test }\end{array}$ \\
\hline $\mathrm{NR}_{1}$ & $\mathrm{O}_{1}$ & $\mathrm{X}_{1}$ & $\mathrm{O}_{2}$ \\
\hline $\mathrm{NR}_{2}$ & $\mathrm{O}_{3}$ & $\mathrm{X}_{2}$ & $\mathrm{O}_{4}$ \\
\hline
\end{tabular}

$\mathrm{O}_{1}, \mathrm{O}_{3}$ adalah skor pretest; $\mathrm{X}_{1}$ adalah pembelajaran dengan metode Inquiry; $\mathrm{X}_{2}$ adalah pembelajaran dengan metode Ekspositori; $\mathrm{O}_{2}, \mathrm{O}_{4}$ adalah skor posttest.

Pelaksanaan penelitian pada semester genap tahun 2019/2020 meng-gunakan semua siswa dari 5 kelas X SMKN 12 Samarinda, sebagai populasi, dan sampel penelitian dipilih teknik purposive sampling.

Pemilihan sampel dilakukan dengan atas dasar dua pertimbangan, yaitu (1) dari guru, bahwa kelas yang dipilih sebagai sampel diajar oleh guru matematika yang sama dan menggunakan buku ajar yang sama, (2) berdasar analisis hasil data tes uji tertulis, bahwa data yang diperoleh tidak normal dan tidak homogen sehingga antara kelas $\mathrm{X}$ AK 1 dan X TKJ tidak ada perbedaan yang signifikan. Berdasarkan pertimbangan tersebut, peneliti memilih 2 kelas sebagai sampel dalam penelitian (kelas X TKJ menjadi kelompok eksperimen dan kelas X AK 1 menjadi kelompok kontrol.

Untuk pengambilan data dalam penelitian menggunakan instrumen jenis tes hasil belajar matematika, observasi, dan dokumentasi. Analisis data penelitian meliputi uji asumsi dan uji hipotesis berupa teknik Independent t-test menggunakan bantuan program SPSS 21. 


\section{HASIL PENELITIAN}

Pengumpulan data hasil belajar dilaksanakan setelah siswa diberikan perlakukan. Hasil belajar tersebut berupa nilai yang mengacu pada nilai Kriteria Ketuntasan Minimal (KKM) yaitu sebesar 70.

Tes berisi soal-soal yang berkaitan dengan materi ajar dalam penelitian yaitu pokok bahasan barisan dan deret aritmetika. Hasil belajar yang diperoleh siswa setelah menjadi sebuah nilai dan diinterpretasikan ke dalam kriteria hasil belajar berikut.

\section{A. Nilai Pretest}

1. Nilai Pretest Kelas Eksperimen

Pretest dilakansakan 1 kali pad atanggal 13 Februari 2020 di kelas X TKJ (kelas ekperimen) dengan alokasi waktu $2 \times 45$ menit. Berda-sarkan data yang diperoleh, nilai rata-rata hasil pretest dari 28 siswa sebesar 49,07; standar deviasi 17,7 ; nilai maksimum 72,5 dan nilai minimum 10. Selain itu, tidak ada siswa yang nilainya melebihi KKM yaitu 70 .

2. Nilai Pretest Kelas Kontrol

Pretest dilaskanakan 1 kali pada tanggal 12 Februari 2020 dikelas X AK1 (kelas kontrol) dalam rentang waktu $2 \times 45$ menit. Berdasarkan data yang berhasil dikumpulkan, nilai ratarata hasil pretest siswa sebanyak 23 orang sebesar 47,06; standar deviasi 17,24; nilai maksimum 70 dan nili minimum 6,25. Selain itu, tidak ada siswa yang memperoleh nilai melebihi dari KKM yaitu 70 .

Hasil pretest kelas ekperimen dan kelas kontrol dapat dilihat pada tabel 2.
Tabel 2. Hasil Pretest Kelas Eksperimen dan Kelas Kontrol

\begin{tabular}{|c|c|c|}
\hline \multirow{2}{*}{ Nilai } & \multicolumn{2}{|c|}{ Kelas } \\
\cline { 2 - 3 } & X TKJ & X AK1 \\
\hline Rata-Rata & 49,07 & 47,06 \\
\hline Standar Deviasi & 17,73 & 17,24 \\
\hline Max & 72,5 & 70 \\
\hline Min & 10 & 6,25 \\
\hline
\end{tabular}

Berdasarkan nilai pretest kedua kelas, yaitu $X$ TKJ serta $X$ AK1, disimpulkan bahwa kedua kelas tersebut memiliki ratarata nilai yang masih dibawah KKM.

\section{B. Nilai Postest}

1. Nilai Posttest Kelas Eksperimen

Posttest dilakukan 1 kali pad atanggal 12 Maret 2020 di kelas X TKJ sebagai kelas ekperimen dengan waktu $2 \times 45$ menit. Nilai rata-rata hasil posttest dari 28 orang sebesar 63,12; standar deviasi 20,77; nilai maksimum 95 dan nilai minimum 22,5. Berdasarkan nilai posttest siswa kelas X TKJ yang memperoleh nilai melebihi KKM sebanyak 10 siswa.

2. Nilai Postest Kelas Kontrol

Postest dilaksanakan 1 kali pada tanggal 11 Maret 2020 di kelas X AK1 sebagai kelas control dalam waktu $2 \times 45$ menit. Berdasarkan data penelitian, nilai rata-rata hasil posttest dari 23 orang sebesar 50,84; standar deviasi 20,48; nilai maksimum 87,5 dan nilai minimum 15. Berdasarkan nilai postets, siswa yang memperoleh nilai melebihi KKM sebanyak 4 siswa.

Hasil posttest siswa kelas ekperimen serta kelas control dapat dilihat pada tabel 3. 
Tabel 3. Hasil Postest Kelas Ekspe-rimen dan Kelas Kontrol

\begin{tabular}{|c|c|c|}
\hline \multirow{2}{*}{ Nilai } & \multicolumn{2}{|c|}{ Kelas } \\
\cline { 2 - 3 } & X TKJ & X AK1 \\
\hline Rata-Rata & 63,12 & 50,84 \\
\hline $\begin{array}{c}\text { Standar } \\
\text { Deviasi }\end{array}$ & 20,77 & 20,48 \\
\hline Max & 95 & 87,5 \\
\hline Min & 22,5 & 15 \\
\hline
\end{tabular}

Berdasarkan nilai posttest siswa dapat dinyatakan bahwa kedua kelas memiliki rata-rata kurang dari nilai KKM.

Tabel 4. Nilai Pretest dan Postest Hasil Belajar Siswa Materi Barisan dan Deret Aritmetika

\begin{tabular}{|c|c|c|}
\hline \multirow{2}{*}{$\begin{array}{c}\text { Rata-Rata } \\
\text { Nilai }\end{array}$} & \multicolumn{2}{|c|}{ Kelas } \\
\cline { 2 - 3 } & $\begin{array}{c}\text { Eksperimen } \\
\text { (X TKJ) }\end{array}$ & $\begin{array}{c}\text { Kontrol } \\
\text { (AK1) }\end{array}$ \\
\hline Pretest & 49,07 & 47,06 \\
\hline Posttest & 63,12 & 50,84 \\
\hline
\end{tabular}

Tabel 4 menunjukan bahwa hasil belajar matematika siswa mengalami peningkatan. Kondisi ini terlihat dari nilai ratarata posttest kedua kelas tersebut lebih besar apabila dibandingkan dengan nilai rata-rata pretest.

\section{Uji Normalitas}

Tabel 5. Uji Normalitas Data Pretest Kelas X TKJ

\begin{tabular}{|l|c|c|c|}
\hline \multirow{2}{*}{} & \multicolumn{3}{|c|}{ Kolmogorov-Smirnov } \\
\cline { 2 - 4 } & Stat & df & Sig \\
\hline Nilai & 0,164 & 28 & 0,053 \\
\hline
\end{tabular}

Berdasarkan tabel 5, hasil uji Kolmogorov-Smirnov menunjukkan ni-lai taraf taraf signifikan uji statistik sig $=$ 0,053 . Karena sig $>\alpha$, yaitu $0,053>0,05$ maka $\mathrm{H}_{0}$ diterima atau data pretest kelas eksperimen berdistribusi normal.

Tabel 6. Uji Normalitas Data Pretest Kelas X AK1

\begin{tabular}{|l|c|c|c|}
\hline \multirow{2}{*}{} & \multicolumn{3}{|c|}{ Kolmogorov-Smirnov } \\
\cline { 2 - 4 } & Stat & df & Sig \\
\hline Nilai & 0,176 & 23 & 0,062 \\
\hline
\end{tabular}

Pada tabel 6, hasil uji KolmogorovSmirnov diperoleh taraf signifikan uji statistik sig $=0,062$. Karena nilai sig $>\alpha$, yaitu $0,062>0,05$ maka $\mathrm{H}_{0}$ diterima atau data pretest kelas kontrol (X AK1) berdistribusi normal.

Tabel 7. Uji Normalitas Data Postest Kelas X TKJ

\begin{tabular}{|l|c|c|c|}
\hline \multirow{2}{*}{} & \multicolumn{3}{|c|}{ Kolmogorov-Smirnov } \\
\cline { 2 - 4 } & Stat & df & Sig \\
\hline Nilai & 0,094 & 28 & 0,200 \\
\hline
\end{tabular}

Pada tabel 7, hasil uji KolmogorovSmirnov diperoleh taraf signifikan uji statistik sig $=0,200$. Karena nilai $\operatorname{sig}>\alpha$, yaitu 0,200>0,05 maka $\mathrm{H}_{0}$ diterima atau data posttest kelas eksperimen (X TKJ) berdistribusi normal.

Tabel 8. Uji Normalitas Data Postest Kelas X AK1

\begin{tabular}{|l|c|c|c|}
\hline \multirow{2}{*}{} & \multicolumn{3}{|c|}{ Kolmogorov-Smirnov } \\
\cline { 2 - 4 } & Stat & df & Sig \\
\hline Nilai & 0,107 & 23 & 0,200 \\
\hline
\end{tabular}

Pada tabel 8, hasil uji KolmogorovSmirnov diperoleh taraf signifikan uji statistik sig $=0,200$. Karena nilai sig $>\alpha$, yaitu 0,200 > 0,05 maka $\mathrm{H}_{0}$ diterima atau data posttest kelas eksperimen (X AK1) berdistribusi normal. 


\section{Uji Homogenitas Varians}

Pada tabel 9, uji Levene diperoleh taraf signifikan statistik sig $=0,962$. Karena nilai sig $>\alpha$, yaitu $0.962>0,05$ maka $\mathrm{H}_{0}$ diterima yang berarti data berasal dari populasi dengan varian sama.

Tabel 9. Uji Homogenitas Varians Data Pretest

\begin{tabular}{|c|c|c|c|}
\hline Levene Statistik & df1 & df2 & sig. \\
\hline 0,002 & 1 & 49 & 0,962 \\
\hline
\end{tabular}

Tabel 10. Uji Homogenitas Varians Data Postest

\begin{tabular}{|c|c|c|c|}
\hline Levene Statistik & df1 & df2 & sig. \\
\hline 0,015 & 1 & 49 & 0,904 \\
\hline
\end{tabular}

Pada tabel 10, hasil uji Levene diperoleh nilai sig. $=0,904$. Karena nilai sig $>\alpha$ yaitu $0,904>0,05$ maka $\mathrm{H}_{0}$ diterima atau data berasal dari populasi dengan varian sama.

\section{E. Uji Independent t-Test}

Berdasarkan hasil uji prasyarat yang sudah terpenuhi (data berditribusi normal dan homogen), dilakukan analisis dengan statistik parametrik uji t.

Tabel 11. Hasil Uji Independent $t$-Test

\begin{tabular}{|l|c|c|c|}
\hline & T & df & sig. \\
\hline Varians sama & 2,113 & 49 & 0,040 \\
\hline $\begin{array}{l}\text { Varians tidak } \\
\text { sama }\end{array}$ & 2,116 & 47,337 & 0,040 \\
\hline
\end{tabular}

Berdasarkan tabel 11, nilai uji Independent $t$-Test diperoleh sig. $=0,04$. Karena sig. $<\alpha=0,05$ maka $\mathrm{H}_{0}$ ditolak, artinya tidak ada perbedaan hasil belajar matematika antara siswa yang diberikan pembelajaran menggu-nakan metode Inquiry dengan metode ekspositori untuk
Kelas X SMKN 12 Samarinda. Hasil perhitungan manual, diperoleh $t_{\text {hitung }}=2,113$ dan $t_{\text {tabel }}=2,009$ pada $\alpha=0,05$; karena $t_{\text {hitung }}>t_{\text {tabel }}$ maka $H_{0}$ ditolak atau ada perbedaan antara hasil belajar matematika dari siswa yang diberikan pembelajaran menggunakan metode Inquiry dengan metode ekspositori pada siswa kelas X SMKN 12 Samarinda.

Setelah dilakukan uji lanjut dengan Uji Satu Pihak (Uji pihak kanan) dari skor Posttest Eksperimen ( $n=28$ atau $d f=27$ ), menggunakan Uji- $t$ satu sampel, pada $\alpha=$ $5 \%$; dan skor rata-rata pembanding (skor Posttest Kontrol) 50,848; diperoleh $t_{\text {hitung }}$ $=|-3,277|=3,1277$ dan $t_{\text {tabel }}=1,703$ atau dengan bantuan SPSS diperoleh $t=$ 3,128, dan Sig. $=0,004$. Dengan demikian, Ho ditolak, sehingga dikatakan bahwa rata-rata skor Posttest Eksperimen secara signifikan lebih tinggi dari rata-rata skor Postest Kontrol.

\section{PEMBAHASAN}

Hasil pengujian hipotesis dengan uji $t$ menghasilkan Sig. $<\alpha$ yang berarti ada perbedaan hasil belajar siswa dalam pembelajaran matematika antara menggunakan metode Inquiry dan Ekspositori untuk kelas X SMKN 12 Samarinda tahun pelajaran 2019/2020. Berarti, terjadi perbedaan penerapan metode pembelajaran mempengaruhi hasil bela-jar materi matematika siswa. Tampak bahwa rata-rata nilai hasil belajar matematika siswa yang diterapkan menggunakan metode pembelajaran Inquiry dan ekspositori. Dengan demikian perbedaan dalam penerapan metode pembelajaran akan meng-hasilkan perbedaan hasil belajar materi matematika dari siswa. 
Nilai tes akhir siswa pada materi barisan dan deret aritmatika yang menggunakan metode pembelajaran Inquiry menunjukkan bahwa rata-rata siswa di Kelas X TKJ adalah lebih tinggi dari kelas kelas $\mathrm{X}$ AK1 yang menggunakan metode ekspositori.. Hal tersebut diperkuat hasil observasi selama proses penelitian terlihat bahwa siswa di Kelas X AK1 kurang antusias dalam mengerjakan Lembar Kegiatan Peserta Didik (LKPD) yang diberikan peneliti, kebanyakan dari mereka hanya menunggu jawaban dari salah satu kelompok atau salah satu temannya saja. Sebagian tidak memperhatikan penje-lasan guru, hanya sebagian siswa saja yang menyimak penjelasan guru dengan baik. Selain itu mereka juga tidak mau bertanya jika ada materi yang belum dipahami sehingga guru harus lebih aktif dan mengarahkan siswa agar dapat mengerti dan memahami materi yang diajarkan. Siswa kelas X TKJ, tampak lebih antusias dan aktif bertanya saat mengerjakan LKPD.

Kemampuan menangkap materi siswa kelas X TKJ lebih baik dibanding siswa kelas X AK1. Hal itu terlihat pada saat penelitian di kelas $\mathrm{X}$ TKJ siswa cepat mengerti mengenai materi yang diajarkan oleh peneliti, sedangkan pada saat pembelajaran dikelas $\mathrm{X}$ AK1 guru harus mengulang materi 2 sampai 3 kali agar siswa dapat memahaminya. Selain itu, kondisi kelas juga sangat mempe-ngaruhi kegiatan pembelajaran dan hasil belajar matematika siswa. Saat memulai pembelajaran kelas X TKJ lebih kondusif dan mudah diatur untuk memulai materi, sedangkan di kelas X AK1 kurang kondusif dan membutuhkan cukup waktu untuk menenangkan siswa. Di samping itu, juga saat pembelajaran pun siswa di Kelas X AK1 masih saja ada yang bermain, ribut, berdandan, atau mengganggu teman sehingga proses pembelajaran terganggu.

Beberapa penjelasan tersebut dapat memperkuat hasil penelitian ini, yaitu kemampuan matematika untuk siswa di Kelas X TKJ lebih baik daripada nilai siswa di Kelas X AK1. Hal itu dapat diamati pada hasil belajar untuk materi Barisan dan Deret Aritmatika rata-rata siswa $\mathrm{X}$ TKJ lebih tinggi dari siswa kelas $\mathrm{X}$ AK1.

\section{KESIMPULAN}

Kesimpulan hasil penelitian adalah secara signifikan terdapat perbedaan hasil belajar matematika dari siswa yang menggunakan pembelajaran dengan metode Inquiry dan ekspositori kelas $\mathrm{X}$ SMKN 12 Samarinda tahun pelajaran 2019/2020. Hasil belajar menggunakan metode Inquiry lebih baik daripada metode Ekspositori.

\section{DAFTAR PUSTAKA}

Chairani, Z. (2016). Metakognisi Siswa Dalam Pemecahan Masalah Matematika Yogyakarta: Deepublish.

Hamalik, O. (2001). Proses Belajar Mengajar. Jakarta: Djambatan.

Hamiyah, N, \& Jauhar, M. (2014). Strategi Belajar Mengajar di Kelas. Jakarta: Prestasi Pustaka.

Hariwijaya \& Surya. (2007). Adven-tures In Math Tes IQ Mate-matika. Yogyakarta: Tugu. 
Kesuma, D. (2010). Contextual Teaching and Learning. Yogya-karta: Rahayasa.

Mulyasa, E. (2013). Menjadi Guru Profesional: Menciptakan Pembelajaran Kreatif dan Menyenangkan. Bandung: Remaja Rosdakarya.

Purwanto. (2009). Evaluasi Hasil Belajar. Yogyakarta: Pustaka Belajar.

Sagala, S. (2010). Konsep dan Makna Pembelajaran Untuk Mem-bantu Memecahkan Problematika Belajar dan Mengajar. Bandung: Alfabeta.

Sugiyono. (2017). Metode Penelitian Pendidikan: Pendekatan Kualita-tif, Kuantitatif, dan $R \& D$. Ban-dung: Alfabeta.

Sumantri, M. (2015). Strategi Pembelajaran. Jakarta: Rajagrafindo Persada.

Syah, M. (2010). Psikologi Pendidikan. Bandung: Remaja Rosdakarya 
| Jurnal PRIMATIKA, Volume 10, Nomor 2, Desember 2021

116 Perbedaan Hasil Belajar Matematika Siswa Menggunakan Metode Inquiry Dan Ekspositori Sugeng - Lina Andriani - PM Labulan 